\title{
Patient under Investigation for COVID-19 Undergoing Appendectomy at Songklanagarind Hospital
}

\author{
Pannawit Benjhawaleemas, M.D., Maliwan Oofuvong, M.D., Ph.D., \\ Nussara Dilokrattanaphichit, B.N., Wiparat Juthasantikul, B.Sc., \\ Pannipa Phakam, B.N.S., Maliwan Oearsakul, B.N.S.
}

Department of Anesthesiology, Faculty of Medicine, Prince of Songkla University, Hat Yai, Songkhla 90110, Thailand. Received 13 June 2020 • Revised 30 June 2020 • Accepted 2 July 2020 • Published online 2 November 2020

\begin{abstract}
:
We report the first case of a patient under investigation for the 2019 novel coronavirus (COVID-19) who needed an open appendectomy at Songklanagarind Hospital. Spinal anesthesia was performed uneventfully. The preparation of the operating room as well as the anesthesia team and equipment are discussed.
\end{abstract}

Keywords: COVID-19, emergency surgery, patient under investigation, spinal anesthesia, team preparation

Contact: Assoc. Prof. Maliwan Oofuvong, M.D, Ph.D.

Department of Anesthesiology, Faculty of Medicine, Prince of Songkla University,

Hat Yai, Songkhla 90110, Thailand.

E-mail: oomaliwa@gmail.com

Hosting by Prince of Songkla University. All rights reserved.

This is an open access article under the CC BY-NC-ND license

(http://www.jhsmr.org/index.php/jhsmr/about/editorialPolicies\#openAccessPolicy).

J Health Sci Med Res 2021;39(2):163-167 doi: 10.31584 jhsmr.2020770 www.jhsmr.org 


\section{Introduction}

The outbreak of the 2019 novel coronavirus (COVID-19) was declared as a global health emergency by World Health Organization on January 30, 2020. ${ }^{1,2}$ On February 26, 2020 it spread all over the world with 50 countries affected ( 80,000 confirmed cases) according to the monitoring system of Johns Hopkins University. ${ }^{1}$ In Thailand, the number of confirmed cases was around 40 according to the Thai Public Health report. While the Songklanagarind Hospital policy for managing COVID-19 was still being developed in mid-March 2020, the first suspected COVID-19 case requiring surgery had arrived. We report the first case of a patient under investigation for COVID-19 who needed an open appendectomy at Songklanagarind Hospital. The case study (Protocol \#6322781) was approved by the Human Research Ethics Committee, Faculty of Medicine, Prince of Songkla University on June 3, 2020.

\section{Case report}

A 27-year-old Thai female was diagnosed with acute appendicitis at 4.30 p.m. on March 19, 2020 and was scheduled for an open appendectomy. She had travelled to the State of Selangor, Malaysia 2 days prior to admission. She had a fever (38 degrees Celsius) with right lower quadrant pain since 8.00 a.m. on the day of admission. There was no other symptom of respiratory tract infection. Therefore, the patient was investigated for COVID-19 by an infectious disease specialist from the department of internal medicine. Upon entering the emergency room, a surgical mask was given to the patient and she was instructed to place it over her face, to which she promptly complied. Since the situation was urgent, the patient was prepared for emergency appendectomy before the result of the polymerase chain reaction (PCR) (nasal swab) for COVID-19 was known. At 4.30 p.m., activation of an operating room (OR) was requested and an anesthesia team was notified. At the time, hospital policy on the management of patients with suspected COVID-19 had not been fully implemented. The hospital director and the head of the Anesthesia Department were notified. Since negative pressure OR are not available in our hospital, an OR for performing gastrointestinal endoscopy, which has a negative pressure environment, was used to manage this case. At 6.00 p.m., the OR, anesthesia equipment, anesthetic agent, and anesthesia personnel were fully prepared. The anesthesia machine and anesthesia equipment were covered by transparent plastic bags to minimize droplet exposure. A minimally sufficient OR team performed the operation with minimally sufficient operating/anesthesia equipment to minimize the risk of viral contamination. Full-body personal protective equipment (PPE) was worn by the surgical, anesthesia, and nursing assistant teams, and a powered air-purifying respirator (PAPR) was used by all personnel. Two anesthesia teams were involved in this case. One team worked with the patient during the operation while a back-up team stood by outside the room in case of an emergency or if more anesthesia supplies (personnel, drug, equipment) were required. Each team consisted of one anesthesiologist and one anesthetist nurse.

The patient wore a surgical mask at the patient under investigation (PUI) for COVID-19 ward, during transferal to the OR at 8.00 p.m. and throughout the operation. Spinal anesthesia was performed using $0.5 \%$ hyperbaric bupivacaine $3 \mathrm{~mL}$ (Figure 1). The levels of anesthesia and analgesia 10 minutes after spinal anesthesia were T6 and T4, respectively. The operation went well apart from two episodes of shivering which occurred 10 minutes and 1 hour after commencement of anesthesia. A low flow oxygen cannula (3 liters per minute) under surgical mask was applied to the patient when shivering began until the operation was finished. Pethidine was given intravenously to treat each episode. The operation time was 40 minutes. An anesthesia back- 


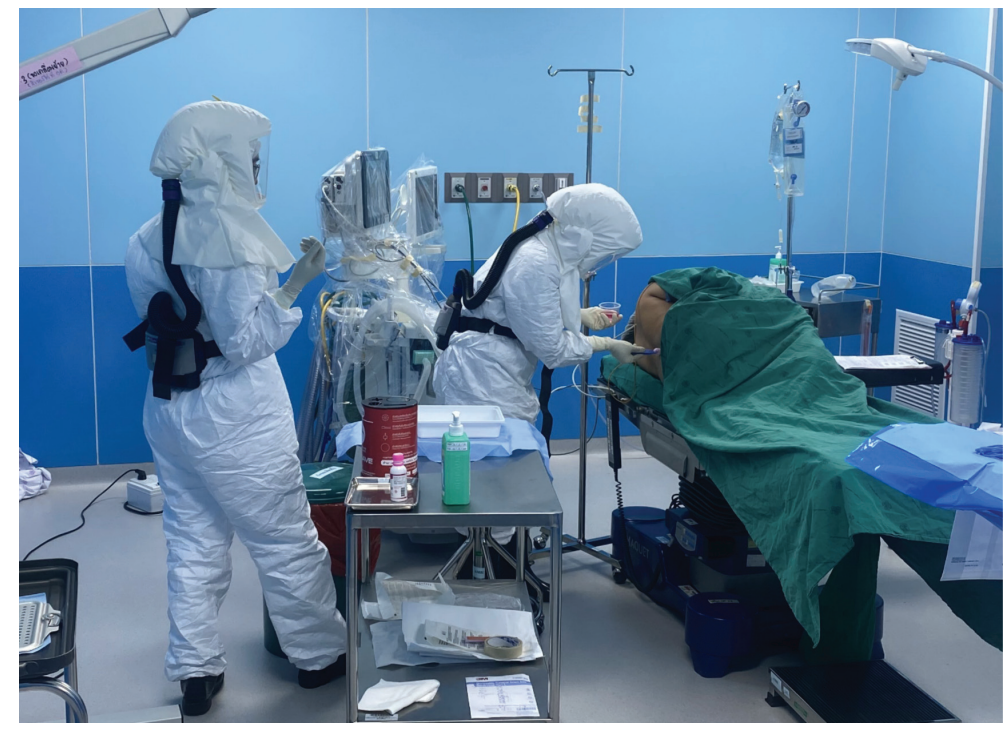

Figure 1 Spinal anesthesia was performed by an anesthesiologist under a powered air-purifying respirator with coverall

up team was called twice to supply pethidine and $0.5 \%$ bupivacaine local injection. The patient recovered in the OR for 30 minutes after the operation. The anesthesia level decreased to T10 with stable hemodynamic parameters before the patient was transferred, wearing a surgical mask, to the PUI for COVID-19 ward. The anesthesia time, including the recovery process, was 1 hour and 10 minutes. No postoperative complications were reported. After the operation, high-touch surfaces on the anesthesia machine (oxygen flow meter), monitor (3 lead electrocardiography cable, sphygmomanometer cuff and pulse oximeter probe) and anesthesia work area were cleaned and disinfected with $0.5 \%$ sodium hypochlorite. The PUI OR was closed until the disinfection of every surface in the OR was completely cleaned. The PCR swab came back at 2 a.m. the next morning and was negative for COVID-19. Verbal informed consent was obtained from the patient to report this case.

\section{Discussion}

On March 18, 2020 Songklanagarind Hospital was alerted of the coronavirus outbreak. A hospital policy for managing COVID-19 was still being devised while the first suspected COVID-19 case requiring emergency surgery was being admitted. The location of a negative pressure OR for suspected/confirmed COVID-19 cases was still under consideration (whether it should be in the main OR or outside the main OR). This suspected COVID-19 case was investigated because the patient presented with fever and had travelled to Malaysia, a country was considered to have an increased risk of developing the COVID-19 infection. Acute appendicitis requires surgery within 24 hours after symptoms onset to decrease the risk of complications. ${ }^{3}$ In our practice, appendectomy is often performed within 8 hours after diagnosis, therefore the surgeon did not wait until the result of the PCR swab for COVID-19 was known. 
Our suspected COVID-19 patient was admitted to a negative pressure isolation room on the ward. If the patient required a surgical procedure, a negative pressure OR was considered to be more suitable than a positive pressure one since personnel working in adjacent areas are better protected. ${ }^{4,5}$ Because the back-up surgical and anesthesia team did not wear full-body PPE, surgery took place in a gastrointestinal endoscopy OR which is a negative pressure environment. A hospital in Singapore reported that in their specialized COVID-19 designated OR, which consists of five interconnected rooms, to lessen viral contamination only the ante room and anesthesia induction rooms have negative atmospheric pressures, whereas the OR proper, preparation, and scrub rooms all have positive pressures. ${ }^{6}$ In our hospital, only necessary equipment and anesthetic agents are allowed into the PUI-designated OR whereas the back-up equipment and anesthetic agents were placed outside in the recovery room ready to be transferred into the OR via the ante room if needed. For this case, the back-up anesthesia supply was called for twice, even though all basic anesthesia supplies were checked before the patient arrived.

Standard PPE for attending to suspected or confirmed COVID-19 cases in OR are a N95 mask, disposable OR caps, goggles, disposable fluid-resistant long-sleeved gowns, disposable full-face shields, and at least 2 layers of gloves and boots. ${ }^{7}$ Hand washing is essential before and after donning or doffing PPE. ${ }^{7}$ A PAPR vs PPE with N95 mask might not be different in terms of contamination risk but a PAPR might have greater user satisfaction due to the easier breathing capability. ${ }^{8}$ In fact, the PAPR in our situation was not absolutely necessary because orotracheal intubation or other aerosol-generating medical procedures (non-invasive ventilation, tracheotomy, cardiopulmonary resuscitation, manual ventilation before intubation, and bronchoscopy) were not planned. ${ }^{9}$ Never- theless, PAPR was used in this situation, since the operation may have been prolonged if complications occurred and therefore general anesthesia with orotracheal intubation (aerosol procedure) may have been needed.

We selected spinal anesthesia rather than general anesthesia with orotracheal intubation to lessen the risk of viral transmission. ${ }^{10,11}$ Recommendations based on the current literature regarding safe administration of neuraxial anesthesia for a suspected COVID-19 patient are as follows. ${ }^{11,12}$ First, all patients should wear a surgical facemask to restrict droplet spread. Second, use of supplemental oxygen should be minimized to maintain oxygen saturation. Third, anesthesia staff should be prepared to treat hypotension at any time. Fourth, use of sedative medication should be minimized, especially for cases with preexisting respiratory problems. Finally, adequate PPE for medical personnel should be used to reduce exposure to airborne droplets. For this case, a high level of analgesia (at least T6 blockage) was obtained to enable the surgeons to adequately perform the operation and make the patient as comfortable as possible during manipulation of the peritoneum without the use of sedative agents. The patient tolerated the high level of anesthesia reasonably well with no adverse events, including hypotension. Low dose intravenous pethidine and low flow supplementary oxygen via nasal cannula were given to treat shivering. In other circumstances, for example if a patient presents with respiratory symptoms, general anesthesia with orotracheal intubation should be administered, rather than spinal anesthesia, to reduce the risk of respiratory failure (impending pneumonia) during the operation. ${ }^{7}$ For this case, even though spinal anesthesia was performed to minimize viral transmission, an anesthesia back-up team should be standing by in case of an emergency or if anesthesia supplies are required. ${ }^{11}$ 


\section{Conclusion}

Our first suspected COVID-19 case undergoing open appendectomy was managed safely and quickly. The choice of anesthesia was based on the patient's condition and type of operation. A back-up team was used to minimize the risk of adverse events to the patient and anesthesia personnel in this suspected COVID-19 case.

\section{Acknowledgement}

We would like to thank Assistant Professor Edward McNeil for assistance with editing the manuscript.

\section{Funding sources}

Faculty of Medicine, Prince of Songkla University, Hat Yai, Songkhla, Thailand.

\section{Conflict of interest}

The authors have no conflicts of interest.

\section{References}

1. Yi Y, Lagniton PNP, Ye S, Li E, Xu RH. COVID-19: what has been learned and to be learned about the nove coronavirus disease. Int J Biol Sci 2020;16:1753-66.

2. Shereen MA, Khan S, Kazmi A, Bashir N, Siddique R. COVID-19 infection: origin, transmission, and characteristics of human coronaviruses. J Adv Res 2020;24:91-8.

3. Kim M, Kim SJ, Cho HJ. Effect of surgical timing and outcomes for appendicitis severity. Ann Surg Treat Res 2016;91:85-9.

4. Li Y, Zhao R, Zheng S, Chen X, Wang J, Sheng X, et al. Lack of vertical transmission of severe acute respiratory syndrome coronavirus 2, China. Emerg Infect Dis 2020;26: 1335-6.

5. Chow TT, Kwan A, Lin Z, Bai W. Conversion of operating theatre from positive to negative pressure environment. $J$ Hosp Infect 2006;64:371-8.

6. Ti LK, Ang LS, Foong TW, Ng BSW. What we do when a COVID-19 patient needs an operation: operating room preparation and guidance. Can J Anaesth 2020;67:756-8.

7. Zucco L, Levy N, Ketchandji D, Aziz M, Ramachandran SK. Perioperative Considerations for the 2019 Novel Coronavirus (COVID-19). APSF [serial on the Internet]. 2020 Feb [cited 2020 May 26]. Available from: http://www.apsf.org/newsupdates/perioperative-consideratons-for-the-2019-novelcoronavirus-covid-19

8. Verbeek JH, Rajamaki B, ljaz S, Sauni R, Toomey E, Blackwood $\mathrm{B}$, et al. Personal protective equipment for preventing highly infectious diseases due to exposure to contaminated body fluids in healthcare staff. Cochrane Database Syst Rev 2020;4:CD011621.

9. Peng PWH, Ho PL, Hota SS. Outbreak of a new coronavirus: what anaesthetists should know. BJA 2020;124:497-501.

10. Herman JA, Urits I, Kaye AD, Urman RD, Viswanath O. COVID19: Recommendations for regional anesthesia. J Clin Anesth 2020;65:109885

11. Uppal V, Sondekoppam RV, Landau R, El-Boghdadly K, Narouze S, Kalagara HKP. Neuraxial anaesthesia and peripheral nerve blocks during the COVID-19 pandemic: a literature review and practice recommendations. Anaesthesia 2020. doi: 10.1111/anae.15105.

12. Lie SA, Wong SW, Wong LT, Wong TGL, Chong SY. Practical considerations for performing regional anesthesia: lessons learned from the COVID-19 pandemic. Can J Anaesth 2020; $67: 885-92$ 